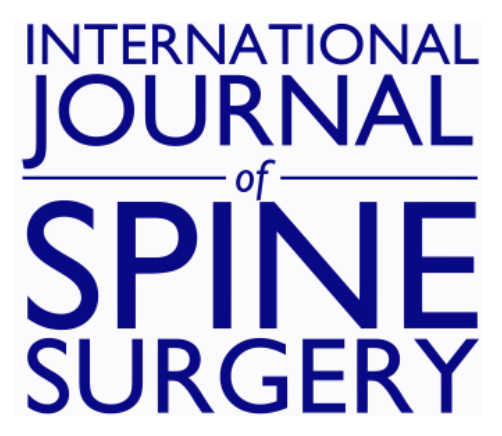

\title{
Radiographic Factors Affecting Lordosis Correction After Transforaminal Lumbar Interbody Fusion With Unilateral Facetectomy
}

CHRISTOPHER T. MARTIN, SHUO NIU, EMILY WHICKER, LAURA WARD and S. TIM YOON

Int J Spine Surg 2020, 14 (5) 681-686

doi: https://doi.org/10.14444/7099

http://ijssurgery.com/content/14/5/681

This information is current as of April 26, 2023.

Email Alerts Receive free email-alerts when new articles cite this article. Sign up at:

http://ijssurgery.com/alerts

The International Journal of Spine Surgery

2397 Waterbury Circle, Suite 1,

Aurora, IL 60504, Phone: +1-630-375-1432 


\title{
Radiographic Factors Affecting Lordosis Correction After Transforaminal Lumbar Interbody Fusion With Unilateral Facetectomy
}

\author{
CHRISTOPHER T. MARTIN, MD,${ }^{1,2}$ SHUO NIU, MD, PHD,${ }^{1}$ EMILY WHICKER, BA, ${ }^{1}$ LAURA WARD, BS, ${ }^{1}$ \\ S. TIM YOON, MD, PHD ${ }^{1}$ \\ ${ }^{I}$ Emory University, Department of Orthopaedics, Atlanta, Georgia, ${ }^{2}$ University of Minnesota, Department of Orthopaedics, Minneapolis, Minnesota
}

\begin{abstract}
Background: The study design was a retrospective cohort study. The objective was to identify preoperative (preop) radiographic features that are associated with increased lordosis correction after transforaminal lumbar interbody fusion (TLIF).

Methods: We retrospectively reviewed a single surgeon series of TLIF performed at L4-5 since 2010. The surgical technique involved unilateral facetectomy and insertion of a banana-type cage. A total of 107 cases were available with plain radiographs, and 62 with a preop computed tomography (CT) scan. We compared segmental lordosis correction between the preop and 6-week postoperative radiographs. Patients were divided into groups of those with or without more than $5^{\circ}$ lordosis correction. Radiographic features were then compared, and a multivariate analysis was performed.

Results: The mean lordosis correction of the entire cohort was $2.5^{\circ}$ (range $=-9^{\circ}$ to $16^{\circ}$ ). The percentage of patients with a vacuum disc on the preop CT $(40 \%$ vs $10 \%, P=0.01)$ was higher in the group with greater than $5^{\circ}$ lordosis correction, whereas the mean preop segmental lordosis $\left(14.3^{\circ}\right.$ vs $\left.18.6^{\circ}\right)$ and the preop segmental disc angle $\left(6.4^{\circ}\right.$ vs $\left.8.4^{\circ}\right)$ were both lower $(P<0.05$ for each). The percentage of patients with a Meyerding grade of 2 or higher $(28 \%$ vs $16 \%)$ trended higher but was not significant $(P=0.1)$. There was no significant difference in the mean body mass index, patient age, preop lumbar lordosis, or disc space height.

Conclusions: Patients with a preop vacuum disc sign on CT scan or those with a more kyphotic disc space on preop radiographs were more likely to achieve lordosis correction. This information may be useful in preop planning.

Level of Evidence: 4.

Clinical Relevance: Unilateral TLIF is likely to be neutral or kyphogenic in patients with a segmental disc angle that is neutral or lordotic pre-operatively, but is likely to increase segmental lordosis in patients with a disc angle that is kyphotic pre-oepratively.
\end{abstract}

Lumbar Spine

Keywords: TLIF, lordosis, segmental alignment, deformity

\section{INTRODUCTION}

Significant emphasis has been placed on restoring sagittal balance after lumbar spine procedures. Sagittal imbalance increases the muscular forces required to stay upright and is closely associated with worsening back pain and lower patientreported outcome measures. ${ }^{1}$ Historically, sagittal imbalance has been associated with long fusion constructs. ${ }^{2}$ However, short segments that are fused in kyphosis increase the amount of lordosis required at adjacent segments. This adjacent segment hyperextension may compensate for a short time, but as the adjacent segment deteriorates, the compensatory effect is lost, and global imbalance can subsequently occur. ${ }^{3}$ Thus, lordosis correction has been emphasized even in short segment constructs. ${ }^{4}$

Transforaminal lumbar interbody fusion (TLIF) is a well-established technique that is reported to provide better lordosis correction than posterolateral fusion alone. ${ }^{5}$ However, the amount of segmental lordosis achieved after TLIF is variable, with some authors reporting slight segmental kyphosis after TLIF. $^{6-9}$ Clearly, technique-related factors influence the amount of lordosis that is possible, such as placing the cage anteriorly in the disc space or performing bilateral facetectomies. However, it is the authors' experience that, even in cases with 
Table 1. Demographics.

\begin{tabular}{|c|c|c|c|}
\hline & $\begin{array}{c}\text { Group With }>5^{\circ} \text { Segmental } \\
\text { Lordosis Correction }(n=32)\end{array}$ & $\begin{array}{c}\text { Group With }<5^{\circ} \text { Segmental } \\
\text { Lordosis Correction }(n=75)\end{array}$ & $P$ Value \\
\hline Age, mean (SD) & $59.67(21.65)$ & $65.27(11.25)$ & 0.17 \\
\hline \multicolumn{4}{|l|}{ Sex, n $(\%)$} \\
\hline Female & 19/32 (59) & $39 / 75(52)$ & 0.48 \\
\hline Male & $13 / 32(41)$ & $36 / 75(48)$ & \\
\hline \multicolumn{4}{|l|}{ Race, n (\%) } \\
\hline African American & $16 / 32(50)$ & $15 / 75(20)$ & 0.003 \\
\hline Asian & $0 / 32(0)$ & $4 / 75(5)$ & \\
\hline Caucasian & $15 / 32(47)$ & $54 / 75(72)$ & \\
\hline Hispanic & $0 / 32(0)$ & $1 / 75(1)$ & \\
\hline Unknown & $1 / 32(3)$ & $1 / 75(1)$ & \\
\hline Body mass index, mean $\pm \mathrm{SD}$ & $28.24 \pm 4.8(\mathrm{n}=16)$ & $29.22 \pm 5.66(\mathrm{n}=46)$ & 0.51 \\
\hline
\end{tabular}

Bold indicates $P<.05$.

identical surgical technique, the amount of lordosis achieved is somewhat variable.

Thus, we hypothesized that certain radiographic characteristics would be associated with the postoperative radiographic outcomes. We retrospectively reviewed a consecutive series of 107 cases of TLIF performed with unilateral facetectomy at L4-5 by a single surgeon. The findings should be useful in preoperative (preop) planning and patient counseling.

\section{METHODS}

\section{Patient Selection}

This review was approved by the institutional review board. We retrospectively identified 107 consecutive cases of L4-5 decompression and fusion with TLIF and unilateral facetectomy performed by the senior author between 2010 and 2015. We excluded multilevel fusions, preop infection, revision fusion surgeries, fusions for trauma, or fusions for tumors.

Of these, there were 100 patients with a diagnosis of degenerative spondylolisthesis and stenosis, 1 patient with isthmic spondylolisthesis, 4 patients with an L4-5 facet cyst, and 2 patients with a recurrent L4-5 disc herniation. The patients reported symptoms of radiculopathy, neurogenic claudication, back pain, or some combination thereof. There were 49 men and 58 women. Body mass index (BMI) measurements were calculated from height and weight measurements taken by nursing staff in clinic, and 62 patients had these numbers available, with a mean BMI of 29 across the complete cohort. Age and race were also recorded (Table 1).

\section{Surgical Technique}

All procedures were performed by the same surgeon using a similar technique for cage placement and instrumentation. The patients were positioned prone on a Jackson table with the hips extended to increase the resting lordosis. In 21 patients, the exposure was completed through a paramedian Wiltse approach, and the remaining 87 had a standard midline exposure. After exposure, a central decompression was performed, and then the facet on the more symptomatic side was removed with a high-speed burr. The exiting L4 and traversing L5 nerve roots were identified and protected, and the disc space was prepared in the standard fashion with a combination of endplate shavers and curettes. After sizing, a banana-shaped polyetheretherketone cage was impacted (Cresecent cage from Medtronic or Talos cage from Meditech). The disc space was bone grafted with local autograft bone and bone graft extender (allograft cancellous bone or ceramic composite graft). The transverse process of L4 and L5 were decorticated, and local autograft with bone graft extender was placed across the transverse processes. Then bilateral pedicle screws were placed. An appropriately sized rod was measured, and the set screws were tightened over the rod. No attempt was made to compress over the rods for additional lordosis correction beyond what was achieved from positioning on the table.

\section{Radiographic Measurements}

All 107 patients had preop and 6-week postoperative digital lumbar radiographs available (General Electric Healthcare, Centricity, Chicago, IL). We used the Cobb angle function to measure the 

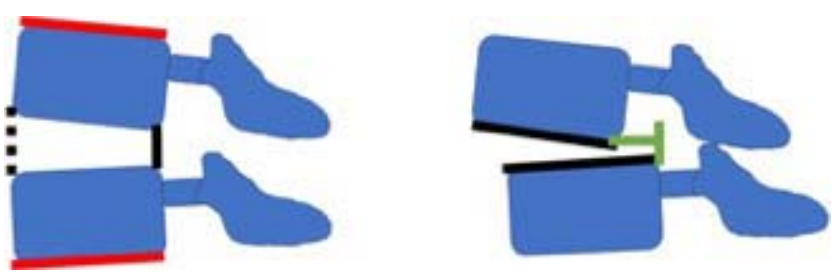

Figure 1. Radiographic measurements. Segmental lordosis (left, Cobb angle between red lines), disc space height (left, dotted black anteriorly and solid black posteriorly), segmental disc angle (right, Cobb angle between black lines), and Meyerding grading (right, green lines).

overall lumbar lordosis from L1-S1, the segmental lordosis at L4-5, and the segmental disc angle at L4-5. In addition, we used the ruler function to measure the disc space height anteriorly at L4-5, the disc space height posteriorly at L4-5, and the Meyerding grade (Figure 1). A total of 62 patients had preop computed tomography (CT) scans available, and these images were reviewed to verify the presence or absence of a vacuum disc. The measurements were performed by an orthopaedic research fellow and reviewed by a fellowship-trained orthopaedic spine surgeon. Standard definitions of each measurement were agreed upon before imaging review (Addendum 1), and each radiographic reviewer attended a 2-hour training session in order to help ensure standardized measurements across each reviewer.

\section{Analysis}

For the univariate analysis, patients were divided into cohorts of those who achieved greater than or equal to $5^{\circ}$ of lordosis correction and those who achieved less than $5^{\circ}$ correction. Five degrees was chosen because it has been accepted as an indicator of true radiographic change in scoliosis measurements. ${ }^{10}$ A student's $t$ test was used for the continuous variables, and a $\chi^{2}$ test was used for the categorical values to compare patient demographics and radiographic characteristics. Finally, we used a multivariate analysis to identify independent radiographic predictors of increased lordosis correction after TLIF. We included all variables with at least $80 \%$ data completion. Based on these criteria, the presence or absence of a vacuum disc could not be included in the multivariate analysis.

\section{RESULTS}

\section{Demographics}

Patient age and BMI as well as the gender distribution were similar across the 2 cohorts $(P>$ 0.05 for each). There was a higher percentage of Caucasians in the group with less than $5^{\circ}$ lordosis correction $(P=0.003$; Table 1$)$.

\section{Univariate Radiographic Analysis}

The mean lordosis correction of the entire cohort was $2.5^{\circ}$ (range $=-9^{\circ}$ to $16^{\circ}$ ). The percentage of patients with a vacuum disc on the preop CT $(40 \%$ vs $10 \%, P=0.01$ ) was higher in the group with greater than $5^{\circ}$ correction, whereas the mean preop segmental lordosis $\left(14.3^{\circ}\right.$ vs $\left.18.6^{\circ}\right)$ and the preop segmental disc angle $\left(6.4^{\circ}\right.$ vs $\left.8.4^{\circ}\right)$ were both lower $(P<0.05$ for each; Table 2$)$. The percentage of patients with a Meyerding grade of 2 or higher $(28 \%$ vs $16 \%)$ trended higher but was not significant $(P=$ $0.1)$. There was no significant difference in the mean preop lumbar lordosis or disc space height (anterior or posterior). Postoperatively, the segmental lordosis was similar at the operated segment in both groups $\left(20.4^{\circ}\right.$ vs $\left.18.6^{\circ}, P=0.16\right)$.

\section{Multivariate Radiographic Analysis}

Evaluating each variable independently, there was no significant effect of the preop lumbar lordosis, Meyerding grade, or segmental disc angle. However, increased preop segmental kyphosis was associated with a higher likelihood of obtaining

Table 2. Radiographic measurements.

\begin{tabular}{|c|c|c|c|}
\hline & $\begin{array}{c}\text { Group With }>5^{\circ} \text { Segmental } \\
\text { Lordosis Correction }(n=32)\end{array}$ & $\begin{array}{l}\text { Group With }<5^{\circ} \text { Segmental } \\
\text { Lordosis Correction }(n=75)\end{array}$ & $P$ Value \\
\hline Preop vacuum disc, no./total $(\%)$ & $4 / 42(10)$ & $8 / 20(40)$ & 0.01 \\
\hline Preop lumbar lordosis, mean $\pm \mathrm{SD},{ }^{\circ}$ & $52.5 \pm 9.3,(\mathrm{n}=75)$ & $51.4 \pm 10.6,(n=32)$ & 0.6 \\
\hline Preop segmental lordosis, mean $\pm \mathrm{SD},{ }^{\circ}$ & $18.6 \pm 6.4,(\mathrm{n}=75)$ & $14.3 \pm 5.7,(n=32)$ & 0.001 \\
\hline Preop segmental disc angle, mean $\pm \mathrm{SD},{ }^{\circ}$ & $8.4 \pm 4.2,(\mathrm{n}=75)$ & $6.4 \pm 4.6,(\mathrm{n}=32)$ & 0.045 \\
\hline Preop disc space height, mean $\pm \mathrm{SD}$, anterior $/ \mathrm{mm}$ & $12.0 \pm 4.5,(n=75)$ & $10.2 \pm 4.2,(\mathrm{n}=32)$ & 0.06 \\
\hline Preop disc space height, mean $\pm \mathrm{SD}$, posterior $/ \mathrm{mm}$ & $6.3 \pm 2.3,(\mathrm{n}=75)$ & $6.1 \pm 2.0,(\mathrm{n}=32)$ & 0.7 \\
\hline Preop segmental translation, mean $\pm \mathrm{SD}, \mathrm{mm}$ & $6.2 \pm 5.4,(\mathrm{n}=42)$ & $5.8 \pm 7.0,(\mathrm{n}=21)$ & 0.8 \\
\hline Mean preop slippage grade, mean $\pm \mathrm{SD}$, Meyerding grading & $1.0 \pm 0.5,(\mathrm{n}=75)$ & $1.0 \pm 0.7,(\mathrm{n}=32)$ & 0.9 \\
\hline Patients with Meyerding grade of 2 , no./total $(\%)$ & $12 / 75(16)$ & $9 / 32(28)$ & 0.15 \\
\hline
\end{tabular}

Abbreviation: Preop, preoperative. Bold indicates $P<.05$. 
Table 3. Multivariate analysis.

\begin{tabular}{llll}
\hline Variable & OR $^{\mathbf{a}}$ & $\mathbf{9 5 \%}$ CI & P Value \\
\hline Preop lumbar lordosis & 1.05 & $(0.992,1.116)$ & 0.09 \\
Preop segmental lordosis & 0.85 & $(0.763,0.955)$ & $\mathbf{0 . 0 0 6}$ \\
Preop segmental disc angle & 0.94 & $(0.81,1.083)$ & 0.38 \\
Preop slippage grade & 0.5 & $(0.207,1.202)$ & 0.12 \\
\hline
\end{tabular}

Abbreviations: CI, confidence interval; OR, odds ratio; preop, preoperative. Bold indicates $P<.05$.

${ }^{\mathrm{a}}$ This OR is for every 1 unit increase, controlling for all other variables.

postoperative lordosis correction. Specifically, for every $1^{\circ}$ increase in preop segmental lordosis, the odds of obtaining greater than $5^{\circ}$ postoperative lordosis correction decreased by $0.85(P=0.006$; Table 3).

\section{DISCUSSION}

Few prior studies have investigated the predictive value of preop radiographs and patient characteristics in predicting the expected lordosis correction after a TLIF. In this study, we found that a disc space that was kyphotic preop or the presence of a preop vacuum disc were associated with greater lordosis correction after TLIF. Several findings merit further discussion.

The mean segmental lordosis correction in our study was $2.5^{\circ}$. This finding is in line with prior studies, which have concluded that segmental lordosis correction after TLIF with a unilateral facetectomy is negligible on average. ${ }^{5,6}$ However, the overall range of segmental lordotic change was quite variable, and in some patients, the TLIF was actually kyphogenic (range of change in segmental lordosis $=-9^{\circ}$ to $16^{\circ}$ ). While not every patient with an L4-5 problem requires a substantial increase in lordosis, we generally try to avoid creating kyphosis in this anatomic region. Indeed, one of the key pieces of rationale for using an interbody device, as opposed to posterolateral fusion alone, is that the presence of the interbody decreases the likelihood of causing segmental kyphosis. ${ }^{5}$ A similar surgical technique was used in each case. In our surgeries, the patients are placed on a Jackson frame with the hips extended to mimic a neutral standing posture. Furthermore, we used a banana-type cage placed anteriorly in the disc space, and anterior cage placement has been associated with increased lordosis correction. ${ }^{11}$ The fact that such variability was seen, in spite of a similar technique in each case, emphasizes the importance of patient-specific factors on the ultimate radiographic outcome.

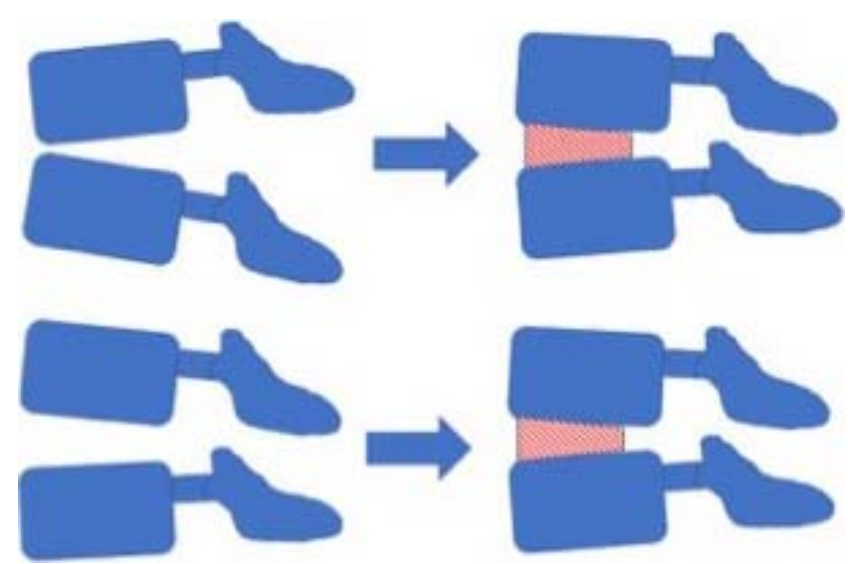

Figure 2. Comparison of the corrective effect of a TLIF cage on a segment with preoperative kyphosis (top) in comparison to a segment with preserved preoperative lordosis (bottom). The kyphotic segment experiences a substantial change in alignment, whereas the lordotic segment does not see much additional change, and both groups end up with a similar final alignment.

In this study, we looked at basic demographic as well as radiographic characteristics. Body mass index, gender, age, and surgical indications were similar across the 2 groups. However, both patients who had segmental kyphosis and those with a preop vacuum disc were more likely to be associated with a minimum of $5^{\circ}$ of lordosis correction in the univariate analysis, and preop segmental kyphosis was predictive in the multivariate analysis. Both groups ended up with similar final segmental alignment postoperatively $\left(18.4^{\circ}\right.$ vs $20.6^{\circ}, P=$ 0.16). In other words, patients with an unstable kyphotic segment tended to have more correction. In these cases, the TLIF cage in the disc space helps to realign the segment back to at least neutral. Thus, the overall change is a substantial net positive increase in lordosis. In contrast, the patients who already had a lordotic disc space to begin with did not have much farther to go (Figure 2).

The study does have several weaknesses. Notably, only 64 patients had a preop CT scan available for review. Thus, the presence or absence of a vacuum disc sign could not be included in the multivariate analysis. We suspect that this factor is indeed associated with instability in the segment and therefore a greater ability to impart lordosis during correctional maneuvers, although a more complete dataset would be required for confirmation. Secondly, our inclusion of radiographic variables was not exhaustive, and there may be additional factors that impact lordosis correction. However, we feel the measurements included here represent a reasonable cross-section of those that are commonly used in practice. Third, we included 4 different clinical 
entities from the L4-5 level (100 cases degenerative spondylolisthesis, 4 cases facet cyst, 2 cases recurrent disc herniation, and 1 case isthmic spondylolisthesis), and it is possible that radiographic outcomes vary across these entities. While narrowing the inclusion criteria might have created a more uniform dataset, we feel that, by presenting all operative cases performed at the L4-5 level, we have given the reader an accurate understanding of the true clinical practice and outcomes of the senior surgeon. Further, we chose to measure the postoperative radiographs at the 6 -week timepoint. It is possible that fusion status, specifically a nonunion with subsequent settling, could also affect lordosis correction. However, this study does not assess that impact and looks solely at the immediate postoperative correction. Lastly, this study focused solely on radiographic outcomes. We did not investigate other common clinical parameters, such as blood loss, length of hospital stay, or patient-reported outcome measures, and our data cannot be correlated with those measures.

Certainly, multiple techniques are available for increasing lordosis correction after a TLIF. Notably, placing a cage anteriorly in the disc space with bilateral facetectomies, followed by compression before final rod tightening, would likely result in substantially higher lordosis correction than what was observed here. However, that technique is more surgery, more destabilizing, and not the most frequently used method of TLIF. The goal of this study was not to determine the maximum amount of lordosis correction that could be achieved with a TLIF. Rather, we wished to determine when more segmental lordosis could be achieved using the most common TLIF technique. Notably, preop radiographic factors did influence the radiographic outcome when the technique was performed in a standard fashion with a unilateral facetectomy. We feel these results should be useful in preop planning for TLIF. If a patient has a kyphotic segment but needs only a small overall increase in sagittal alignment, then TLIF with a unilateral facetectomy may be appropriate, and the surgeon can reliably expect that the TLIF will help bring that segment at least back to neutral. However, if the segment is already lordotic and the surgeon hopes to achieve a further increase in lordosis for the purpose of promoting better overall sagittal balance, then an alternative technique could be considered.

\section{REFERENCES}

1. Glassman SD, Bridwell K, Dimar JR, Horton W, Berven $\mathrm{S}$, Schwab F. The impact of positive sagittal balance in adult spinal deformity. Spine (Phila Pa 1976). 2005;30(18):20242029.

2. Lagrone MO, Bradford DS, Moe JH, Lonstein JE, Winter RB, Ogilvie JW. Treatment of symptomatic flatback after spinal fusion. J Bone Joint Surg Am. 1988;70(4):569-580.

3. Masevnin S, Ptashnikov D, Michaylov D, Meng H, Smekalenkov O, Zaborovskii N. Risk factors for adjacent segment disease development after lumbar fusion. Asian Spine J. 2015;9(2):239-244.

4. Radcliff KE, Kepler CK, Jakoi A, et al. Adjacent segment disease in the lumbar spine following different treatment interventions. Spine J. 2013;13(10):1339-1349.

5. Dimar JR, 2nd, Glassman SD, Vemuri VM, Esterberg JL, Howard JM, Carreon LY. Lumbar lordosis restoration following single-level instrumented fusion comparing 4 commonly used techniques. Orthopedics. 2011;34(11):e760-764.

6. Kim SB, Jeon TS, Heo YM, et al. Radiographic results of single level transforaminal lumbar interbody fusion in degenerative lumbar spine disease: focusing on changes of segmental lordosis in fusion segment. Clin Orthop Surg. 2009;1(4):207213.

7. Yson SC, Santos ER, Sembrano JN, Polly DW Jr. Segmental lumbar sagittal correction after bilateral transforaminal lumbar interbody fusion. $J$ Neurosurg Spine. 2012;17(1):37-42.

8. Jagannathan J, Sansur CA, Oskouian RJ Jr, Fu KM, Shaffrey CI. Radiographic restoration of lumbar alignment after transforaminal lumbar interbody fusion. Neurosurgery. 2009; 64(5):955-963; discussion 963-954.

9. Uribe JS, Myhre SL, Youssef JA. Preservation or restoration of segmental and regional spinal lordosis using minimally invasive interbody fusion techniques in degenerative lumbar conditions: a literature review. Spine (Phila Pa 1976). 2016;41 Suppl 8:S50-58.

10. Brooks HL, Azen SP, Gerberg E, Brooks R, Chan L. Scoliosis: a prospective epidemiological study. $J$ Bone Joint Surg Am. 1975;57(7):968-972.

11. Choi WS, Kim JS, Hur JW, Seong JH. Minimally invasive transforaminal lumbar interbody fusion using bananashaped and straight cages: radiological and clinical results from a prospective randomized clinical trial. Neurosurgery. 2018;82(3):289-298.

Disclosures and COI: The senior author (S.T.Y.), reports receiving royalties from Stryker and Meditech Spine and owns stock in Meditech Spine, Medyssey, Phygen, and Alphatec. He has also received nonfinancial support from Medtronic and Nuvasive. The other authors report no conflicts related to the current work.

Corresponding Author: S. Tim Yoon, MD, $\mathrm{PhD}$, Emory University, Department of Orthopaedics, 59 Executive Park South, Suite 3000, Atlanta, 
GA 30329. Phone: (404) 616-4473; Email: styoon@ emory.edu.

Published 11 November 2020

This manuscript is generously published free of charge by ISASS, the International Society for the Advancement of Spine Surgery. Copyright (C) 2020 ISASS. To see more or order reprints or permissions, see http://ijssurgery.com. 